\title{
La gráfica popular, un referente de la identidad del diseño gráfico mexicano
}

Eduardo Galindo Flores ${ }^{1}$, Mónica González Castañeda ${ }^{2}$ y Daniel Rodríguez Medina ${ }^{3}$

\begin{abstract}
Resumen: La gráfica popular es un fenómeno comunicacional que se genera en los medios urbanos y representa el imaginario gráfico de una sociedad así como esencia de su cultura. El análisis y estudio de los elementos plásticos y estéticos que forman parte de la gráfica popular mexicana son fundamentales para entender la identidad del diseño gráfico de este país. En esta investigación se documentan y analizan los principales referentes gráficos que conforman el amplio universo de la gráfica popular urbana, sus actores, sus necesidades así como el aporte en ocasiones involuntario a una estética única y diferencial como pieza de una cultura que se identifica y distingue por sus colores y el dramatismo en sus imágenes al resto de los demás países. Esta investigación se lleva a cabo tomando como fundamento el método histórico, lógico y analítico/sintético. Se muestran sus características, peculiaridades y efectos directos e indirectos en el diseño gráfico mexicano. Los resultados de esta investigación pueden ayudar a construir un marco histórico y referencial de los rasgos fundamentales que dieron origen al diseño gráfico actual, así también ayudará a entender el contexto y las necesidades que lo originaron en las cuales descansa gran parte de su identidad.
\end{abstract}

Palabras clave: Gráfica popular - Cultura - Sociedad - Identidad - Diseño gráfico mexicano.

[Resúmenes en inglés y portugués en las páginas 104-105]

(1) Eduardo Galindo Flores: Licenciado en diseño para la comunicación gráfica (UdeG), Maestro en Diseño y desarrollo de nuevos productos ( $U$ de $G$ ), doctorante en Metodología de la enseñanza (IMEP). Profesor investigador Titular A en el Centro Universitario de Arte Arquitectura y Diseño de la Universidad de Guadalajara y miembro del cuerpo académico 869 "Identificación, Representación y Grafismo en el diseño". Mail: eduardo. galindo@cuaad.udg.mx

(2) Mónica González Castañeda: Maestra en Diseño Gráfico: Análisis y producción de mensajes (IBERO/León) y Licenciada en Diseño para la Comunicación Gráfica (U de G). Actualmente es Profesora investigadora de la U de G en el Centro Universitario de Arte Arquitectura y Diseño, docente de la Lic. En Diseño y Comunicación Gráfica y miembro del cuerpo académico 869 "Identificación, Representación y Grafismo en el diseño". Mail: castamo@yahoo.com 
${ }^{(3)}$ Daniel Rodríguez Medina: Prof. Investigador Titular C, Centro Universitario de Arte, Arquitectura y Diseño; Universidad de Guadalajara. Maestro en los procesos gráficos en la proyectación arquitectónica y Urbana (UdeG). Doctor en Arquitectura (UNAM) Profesor en la Licenciatura de Arquitectura. Maestría. En Ciencias de la Arquitectura. Miembro del Cuerpo Académico CA 869 "Identificación, Representación y Grafismo en el diseño". Mail: daniel.rodriguez@cuaad.udg.mx

\section{Introducción}

Como lo ha mostrado la historia, en todas las sociedades se van forjando códigos a partir de acuerdos que han dando origen a convenciones en diversos grupos de personas con intereses en común, sin embargo algunos han persistido casi intactos desde su origen y otros se han ido moldeando por diversas circunstancias que les afectaron para bien o para mal, en el caso de los códigos visuales y estilísticos, su tránsito en el tiempo ha sido muy benévolo, permitiendo a éste tipo de códigos evolucionar, adaptarse y fusionarse de acuerdo al contexto.

Los códigos que caracterizaron y aún caracteriza a la gráfica popular mexicana tales como el color, la síntesis visual, la composición, el texto y el manejo del lenguaje fueron gestados principalmente desde un contexto político y un pensamiento de igualdad social.

La evolución de dichos elementos influenciaron la gráfica del diseño mexicano en contextos locales y por ende nacionales. Gracias al movimiento de la Gráfica Popular Mexicana el diseño gráfico genera una reinterpretación y desarrollo de sus códigos, acompañada de saberes, técnicas, materiales, procesos e instrumentos que le han permitido establecer una estética-plástica única, muestra de ello son los diversos rótulos de múltiples establecimientos, marcas regionales de toda clase de productos, servicios o bien anuncios que forman parte del paisaje urbano, por lo tanto se irá mostrando a lo largo del presente escrito, algunos ejemplos que evidencian el conjunto de elementos gráficos mas representativos que han sido influencia para el diseño desde que se gestaron circunstancialmente en aquel modesto Taller de la gráfica popular y en otros rincones de la Ciudad de México.

\section{Breve historia de la gráfica popular mexicana}

Cuando se hace referencia a la gráfica popular, se puede pensar en uno de los primeros mediáticos del expresionismo en México, que como es bien sabido, la primera mitad del siglo $\mathrm{XX}$, al igual que otros países en el mundo, dicho país fue protagonista de cambios sociales, que afectarían el grafismo de aquella época, considerando también la influencia francesa por diversos movimientos artísticos como cubismo, expresionismo y el arte Deco entre otros, así como los viajes constantes a Europa por artistas mexicanos o trabajadores de las artes gráficas, la combinación de diversos movimientos y técnicas de impresión 
como la xilografía principalmente, que dio origen a un fructífero y cada vez mas exclusivo lenguaje iconográfico entre los artistas de la época posterior a la Revolución Mexicana, es en éste periodo que reinicia la industria gráfica gracias a la integración de rotulistas, cajistas, linotipistas, impresores, ilustradores, prensistas, litógrafos, grabadores, tipógrafos incluso arquitectos, escultores y pintores con diversos trabajos, desde lo editorial hasta el muralismo o bien algo mas comercial como carteles, volantes, revistas principalmente en ámbitos políticos, sociales y culturales, dicha gráfica posteriormente también se vería beneficiada del exilio de intelectuales del viejo continente a nuestro país.

Poco a poco el arte popular empieza a visualizarse con una identidad propia, con formas, texturas, colores, letras, elementos gráficos de la vida cotidiana desde un arraigo religioso y familiar. Ésta estética callejera en proceso y desarrollo, no sólo mostró lo popular, también originó una prensa de élite que mostraba la prosperidad y estabilidad del país, lo cuál era bien visto y aceptado en Europa y ejemplo para América Latina.

Los grupos y movimientos que fueron surgiendo a partir de la situación que se vivía en México, como el Costumbrismo, entendido por algunos autores como María Esther Pérez, como los relatos de lo cotidiano tipificando casos o personajes específicos, fue un movimiento español impulsado en México por la política, y la educación principalmente, aunque también se retomó en ámbitos de entretenimiento popular, como reflejo de las fiestas, paisajes, homenajes y traiciones para dar paso a publicaciones como El mosaico Mexicano, El recreo de las familias, El apuntador y el Museo Mexicano, convirtiéndose rápidamente en elementos editoriales bien recibidos por su arte y estética editorial que además fue cobijado por la llegada de la Litografía en un momento clave para la divulgación y expansión de los medios impresos.

El sentimiento nacionalista que apenas se construía en ésta época, empieza a crecer y se impulsa fielmente con la obra del maestro José Guadalupe Posada, que con sus casi quince mil grabados se reconoce como el mayor precursor e influencia de la gráfica popular, gracias a su manera de reflejar, desmitificar y acercar la muerte a los mexicanos con su impactante expresionismo plástico de significante simpleza, entretejida con las emociones, alegrías tristezas y temores de la clase popular. En su primer taller instalado en la ciudad de México, su obra siguió manifestando la vida cotidiana, desde lo religioso, principalmente con las memorables calaveras y la caricatura política, influenciado evidentemente por el constumbrismo, abriendo paso a lo que hoy se aprecia y reconoce como gráfica popular. La evolución e importancia de ésta gráfica, continuó permeando a otros sectores de la población, preocupados y ocupados en la situación del país dando origen al Estridentismo -un proyecto utópico de orientación vanguardista inspirado en el futurismo italiano- la Liga de escritores y artistas revolucionarios -LEAR-, el Taller-escuela de artes plásticas -TEAP-, entre muchos otros movimientos, asociaciones, grupos de trabajo y sindicatos. La LEAR fungió como un lugar de aprendizaje y una valiosa oportunidad de dar al arte un nuevo sentido por su contacto con el pueblo definiéndose como una especie de orientador cooperando con la cultura, el arte y la emancipación del proletariado, por éstos principios, se le unieron otros grupos como la Federación de escritores y artistas proletarios -FEAP-, el Sindicato de escritores revolucionarios -SER-, y la Asociación de trabajadores del arte -ATA-, el Taller/Escuela de Artes Plásticas -TEAP-, se autonombraba como un laboratorio experimental de arte revolucionario funcional, de producción gráfica al servicio de 
la lucha diaria de los trabajadores en donde podrían conseguir carteles, telones, rótulos, pinturas transportables, escenografías, pancartas, volantes entre otros elementos que necesitaran para sus huelgas, manifestaciones callejeras, festividades, mítines, marchas, etc. Sin embargo el arte popular y todos los movimientos que se generaron, escuelas, asociaciones o bien piezas gráficas estaban enfocadas hacia una misma identidad, la dureza de las imágenes, la pregnancia, la temática, lo común, lo masivo, lo religioso, la política, lo tradicional, dando soluciones a diversas problemáticas posteriores como lo fue el Movimiento del ' 68 y los Juegos Olímpicos del mismo año, que retoman por herencia y re significan los elementos populares sin perder de vista esa identidad popular que se había venido gestando desde el siglo XIX, pero es hasta éste movimiento en donde se evidencian piezas gráficas mas estructuradas, equilibradas, complejas, armónicas, sintetizadas, con una composición mas jerarquizada y altamente estética, color y textos, pues a ésta fecha ya participaban mas personas instruidas en las artes, comunicación y otras profesiones que personas formadas en oficios.

Así como ya se ha mencionado los antecedentes de la gráfica popular en dicho país no son tan claros, los registros que conforman esta fascinante historia tienen sus orígenes probablemente en la primera mitad del siglo XX con las nacientes ilustraciones y grabados de Manuel Manilla, compañero de taller y posible maestro de José Guadalupe Posada, tal como lo comenta Troconi (2018). Muchos de los trabajos de Manilla son personajes distorsionados y caricaturescos de temas alusivos a la muerte, también figuras de animales con cráneos humanos, personajes de cantinas y múltiples ornamentos en forma de marcos que recuerdan a las influencias traídas desde occidente. La política sin duda fue un tema recurrente en las representaciones de este autor, sus cuadros con temáticas de la lucha de clases fueron abordados con una majestuosidad indudable, escenas dantescas y representaciones incluso oníricas conforman en suma el pequeño universo de la gráfica de este relevante y gran ilustrador, como lo menciona María E. Sánchez en la revista digital Interior gráfico.

Por su parte José Guadalupe Posada (1882), al cual se le atribuyen las mundialmente conocidas catrinas tuvo a bien perfeccionar las temáticas de su antecesor, con una notable técnica y trazo depurado representaba con sátiras a la clase política mexicana, cronista gráfico y representante entonces de una incipiente tradición de ilustradores para publicaciones de carácter nacionalista y popular. Entre sus temáticas principales destacan aquellas de seres de ultratumba, escenas de catástrofes naturales, viñetas que acompañaban corridos revolucionarios, personajes de la vida moderna de aquel entonces y considerables alegorías a la vida cotidiana con sus excesos y banalidades, también se le conoce por hacer crítica a la sociedad y sus aspiraciones a tener una vida europea a quienes representó en forma de calaveras bien vestidas y refinadas.

Si bien a estos primeros ilustradores y grabadores de la época hoy se les considera y circunscribe como precursores en torno a un concepto de gráfica popular cabe mencionar que no fueron los únicos autores de todo lo que circulaba en aquellos días, existen registros fotográficos de diversos establecimientos comerciales de la época donde los rótulos seguramente fueron encomendados a ilustradores anónimos. Las imprentas con su modesta organización y estructura probablemente contaban con personal capacitado para diferentes áreas que incidían en la gráfica de su momento, volantes, anuncios públicos y 
por supuesto las publicaciones editoriales de su tiempo debieron aportar cierta influencia que en consecuencia originaron y explotaron la expresión icónica tipográfica de la época. También el registro fotográfico de la primera mitad del siglo XX demuestra que las tiendas de abarrotes, las farmacias, pulquerías y cantinas entre otros establecimientos del México antiguo tenían en sus fachadas rótulos de diversas características los cuales sin duda se hacían por encargo a artistas gráficos. Según Troconi (2018) hay un componente que existe pero es imposible registrar a lo que se denomina como la adaptabilidad. Resulta necesario mencionar que nuestro país venía de una colonización que tuvo influencias europeas mezcladas con las costumbres y usos de esta nación, posteriormente llegó la independencia y después la revolución, el país se encontraba casi en ruinas y con las ideas liberales y sus reminiscencias progresistas obligaron a que los comercios y propietarios se adaptaran a los recursos y necesidades específicos, si bien no se identifica una profesionalización de lo que hoy algunos denominan Diseño gráfico popular, queda claro que había un grupo de dibujantes y rotulistas de oficio (Ver Figura 1), que conocía el contexto y adecuaban la gráfica según las necesidades que se iban presentando. Esta capacidad es un componente que aunado a la creatividad dieron como consecuencia la plasticidad de la gráfica popular mexicana en sus inicios.



Figura 1. Pulquería Amores de Cupido en la esquina de la avenida Santa María la Redonda, hoy el Eje Central y la Calle del Órgano, en las inmediaciones de la Lagunilla, hacia la década de 1920 (La ciudad de México en el tiempo, 2017, s/p). 


\section{Elementos identitarios fundamentales de la gráfica popular mexicana}

Hablar de la identidad del mexicano es un objeto de estudio fascinante y con una complejidad tal que hasta nuestros días se sigue investigando y escribiendo al respecto para tratar de definirla. Hay una memoria colectiva que hace que se identifique, una huella que difícilmente se puede describir pero que se distingue de las demás culturas. De alguna manera aquello que caracteriza y define a la gráfica mexicana tiene componentes que lo hacen sui géneris, una estética y plasticidad única y con códigos altamente complejos, pero que a su vez son fáciles de identificar y de percibir. Se refiere a una mezcla propia del mestizaje, de los adelantos del mundo moderno y las reminiscencias de nuestras culturas, una extraña fusión que la hace única producto de técnicas propias de la época y de movimientos sociales de gran impacto en la vida de este país.

Para este breve análisis de las características y particularidades de la gráfica popular mexicana y sus componentes que dieron origen a lo que posteriormente se le llamaría diseño gráfico mexicano se tomaron como variables básicamente cuatro elementos fundamentales: la letra, la ilustración, el color y el uso del lenguaje. Aunque no son los únicos, se puede considerar que tienen los elementos necesarios para identificar la plasticidad y estética de este objeto de estudio.

Las letras son elementos constitutivos esenciales en estas grafías, se pueden observar ejemplos que hacen uso de elementos expresivos sorprendentes como son los degradados y añadidos de sombras que emulan la tridimensionalidad y ejercen una fuerza de atracción imposible de evadir como se muestra en la Figura 2. El dibujo de estos rótulos básicamente está realizado con el nombre del establecimiento, también se agregan en la mayoría de los casos el tipo de producto que se vende en él. La forma de representar esta tridimensionalidad es muy variada, puede ser a través de una línea que aparenta la proyección de la sombra de la letra o como el plano dibujado para conferirle dicho atributo.

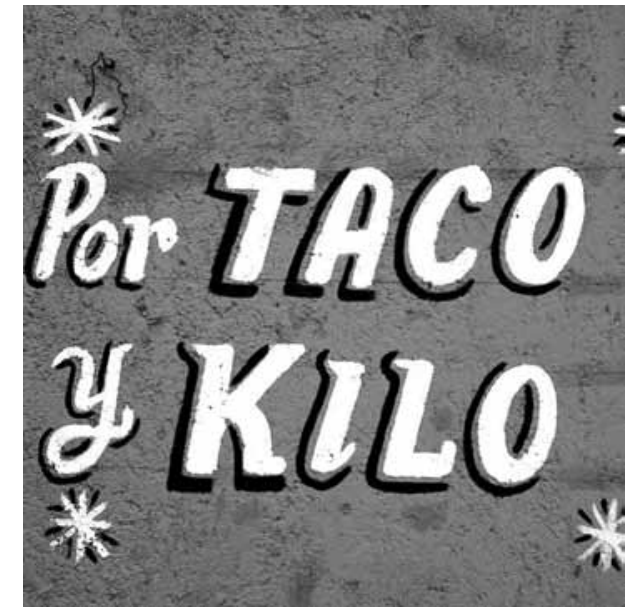

Figura 2. Emulación de sombra en rótulo de puesto callejero (Think Tank, 2016, s/p). 
Estos añadidos de volumen se usan de manera indistinta, puede ser en un anuncio de comida en un puesto callejero hasta en identificadores y marcas (Ver Figura 3) o de agrupaciones musicales, que en cualquiera de los casos su propósito final es el de captar la atención y añadirle cierta personalidad. También se observa que la perspectiva acompaña a muchos de estos letreros, la letra en forma de arco o en aumento progresivo de tamaño ya sea de lado a lado o inclusive con convergencia hacia el centro. Los planos inclinados y la aparente aleatoriedad de los mismos le brindan a la composición un dinamismo íntimamente ligado al aparente desorden. Es importante señalar que detrás de todos estos rótulos y letras dibujadas hay rotulistas con una técnica excepcional que seguramente estaban adiestrados en las artes caligráficas, tal como lo comentan Checa-Artasu y Castro (2008).

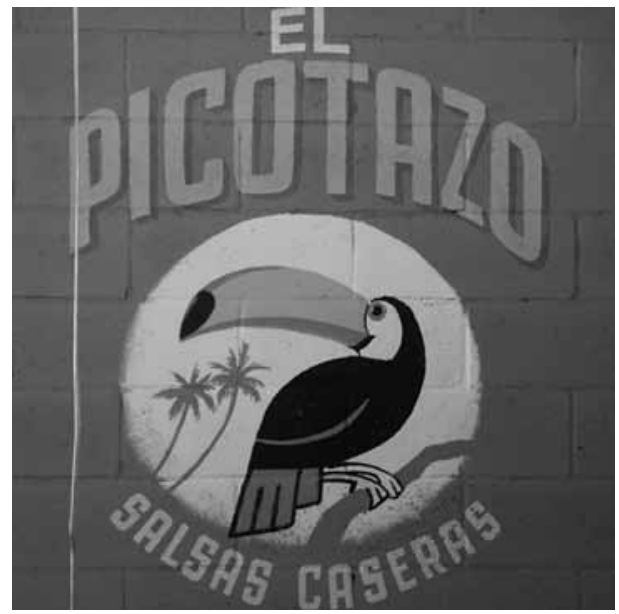

Figura 3. Rótulo de marca para salsas caseras (MXCity, 2016, s/p).

Por otra parte la letra dibujada a mano le confiere una particularidad de crudeza y representación única, aunque este rasgo es compartido con otras manifestaciones gráficas en distintos países en México es evidente la poca preocupación por la precisión en el trazo y se centra más en el impacto producido con el texto. Esto le confiere una fuerza notable además que acentúa el carácter y propósito del texto (Ver Figura 4).

También en ella se pueden encontrar grandes influencias de los tipógrafos y cajistas de aquella época con una gran variedad de estilos y formas, llama particularmente la atención el uso de algunos de ellos como es el caso de las letras Góticas que pareciera en muchos de los casos que su aplicación está totalmente fuera de contexto o que se olvida totalmente de la función signo de la letra. 


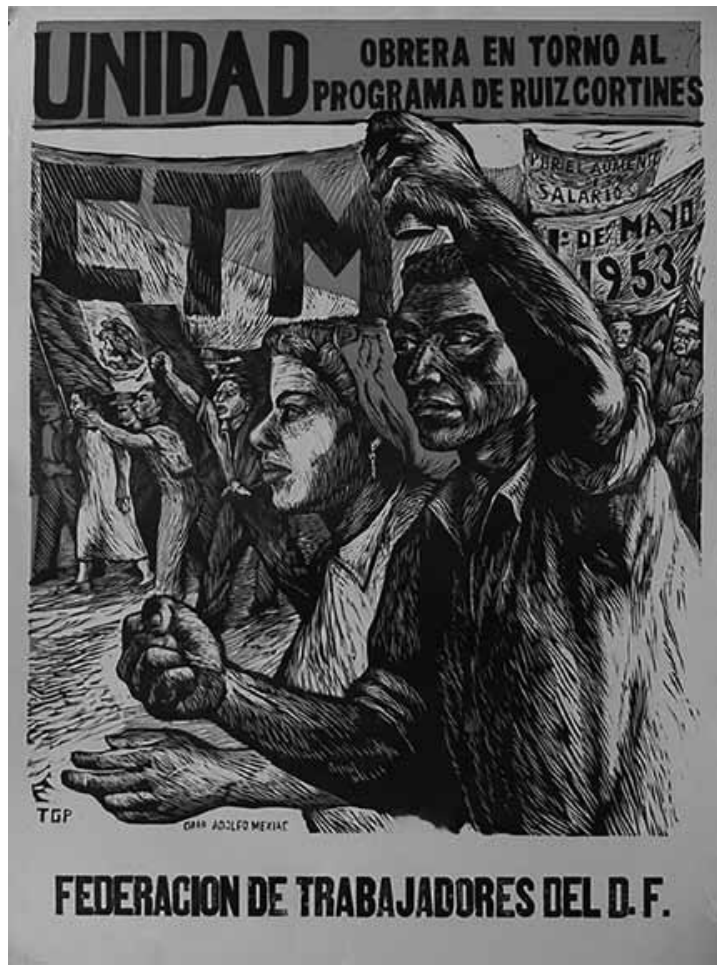

Figura 4. Unidad Obrera en torno al programa de Ruiz Cortines (1953). Poster con grabado de linóleo y caligrafía a dos tintas. Colección de Michael T. Ricker (Gato Pardo, 2017, s/p).

Por otra parte la ilustración es particularmente heterogénea, es difícil clasificar o enumerar las características que componen esta dimensión. Las primeras influencias de los grabadores mencionados con anterioridad permearon hasta cierto punto en la ilustración utilizada en este tipo de gráfica. Se pueden observar que algunas de las técnicas utilizadas emulan la apariencia del grabado de aquellos tiempos, muchos de los dibujos utilizados tienden al hiperrealismo no había en sus comienzos una aparente preocupación por la simplificación o síntesis como un propósito evidente. La profusión de las imágenes es incuestionable, es un rasgo característico de este componente gráfico de aquellos días y que en la actualidad permanece vigente, esta es una propiedad que le confiere una carga identitaria muy fuerte, ese exceso en los detalles, el color y las alegorías aportan una plasticidad muy peculiar. La imagen en la gráfica popular es esencialmente dramática con una carga emotiva exacerbada. Sus personajes en muchos casos parecen salidos o extraídos de una escena teatral o una representación Dantesca. Su carga simbólica deja claro que su propósito no es de complementar o ser un elemento subdominante, sino que tiene como fin ser protagonista y provocar una reacción altamente emotiva en el receptor tal como se puede apreciar en la Figura 5. 


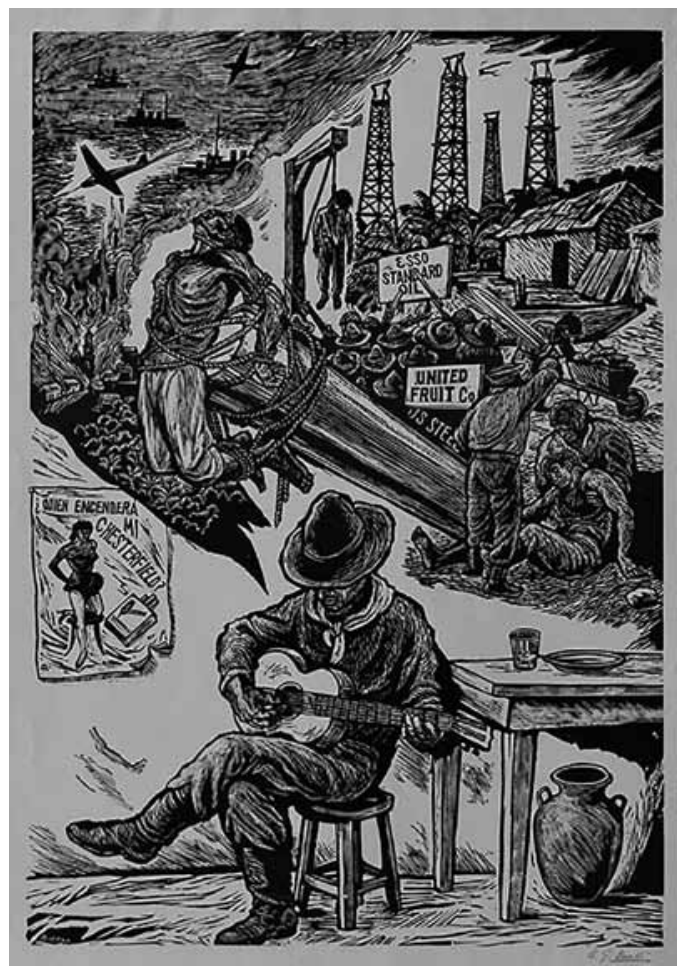

Figura 5. Compañeros extranjeros. Grabado en linóleo (Gato Pardo, 2017, s/p).

Sin embargo en aquellas utilizadas con fines comerciales algunas tienen distintos rasgos, se identifica en diversos casos el uso de metáforas visuales, combinaciones de objetos y animales caricaturizados y llevados al nivel incluso de lo cómico. Su representación en técnicas es disímil la única constante es que se les confiere una importancia preponderante tanto en tamaño como en composición. En general se podría concluir que la imagen es primordial en la gráfica popular, es un recurso que proporciona la vitalidad y atracción suficiente para poder llegar a su propósito. Es la imagen el elemento que aporta la referencia emotiva y simbólica más importante, en ella descansa ese imaginario visual y refuerza en gran medida la huella mnemotécnica necesaria para generar la identidad a la que se ha hecho referencia.

El color se considera como el segundo grado de significación de la forma, sin embargo, en la gráfica popular cobra una vital importancia. En los albores de este grafismo como consecuencia de la técnica de grabado que era la que mayormente se utilizaba, se limitaba a una o dos tintas solamente, esto trajo como resultado acentuar el dramatismo de las imágenes, confiriéndoles un aspecto más sombrío, impactante, pregnante e impresionante, que generaba por consecuencia una atmósfera casi mágica, mística y surrealista. Asociado 
a esto también es evidente que en los sustratos sobre los cuales se imprimían eran papeles que carecían de brillantez, recubrimientos o cualquier proceso de refinamiento. En la etapa del estridentismo se observan ciertas limitantes cromáticas en cuanto a la cantidad de tintas, pero a diferencia a los anteriores aquí se usa con más vitalidad y fuerza en concordancia con el estilo de los gráficos; en ambos casos predominan los colores rojos, negros y ocres. Posteriormente cuando el grafismo fue usado de manera más masiva y comercial el color adquiere otro significado, pero no menos importante, incluso se puede observar que el color toma mayor protagonismo y su significado es tan importante como la forma. Se observa una inmensa variedad de ejemplos donde la audacia en el uso cromático es digna de un análisis más profundo, se puede identificar que en su uso predominan los colores con una alta saturación cromática independiente de la gama utilizada esta variable de saturación es inobjetable a cada una de ellas.

Hay casos como en las carteleras de espectáculos de lucha libre en las cuales se utilizan barridos de dos o tres tintas que proporcionan resultados altamente contrastantes y con fusiones poco imaginables, en ellas se optimiza el recurso y se solucionan los posibles problemas técnicos de registro. En otros ejemplos en los que se requiere rotular la fachada de algún local o establecimiento, ésta se utiliza como un gran lienzo y se aplica color de fondo de una manera totalmente deliberada para captar la atención, de esta forma, se encuentra con grandes dimensiones de colores estridentes y con combinaciones de fondo figura inigualables, pareciera que no hay un juicio o criterio para su uso, son tan alucinantes las mezclas que en algunas se pueden encontrar grandes gamas y tonos en el mismo anuncio. Todo esto le confiere una identidad a la gráfica mexicana incomparable, sólo se pueden observar algunos casos en países caribeños y en algunas latitudes del continente africano. Estos ejemplos se encuentran ya sea en empaques de cigarrillos, volantes, bardas anunciando algún grupo musical, puestos callejeros e incluso revistas de espectáculos como se observa en la Figura 6. La dimensión cromática caracteriza a la gráfica popular mexicana, más aún, la define y alimenta es una dimensión que pareciera ser un grito de libertad ante tanta opresión histórica social, el desenfado de su uso solo puede tener un significado: El grito del aquí estamos, esto somos.



Figura 6. Rótulo de fachada para la cantina El Encanto (Zonezero, 2018, s/p). 
Finalmente la dimensión lingüística es la menos estudiada, pero en esta subyacen las raíces más profundas de la identidad mexicana, en ella se representan las costumbres, los regionalismos, la cultura y sus tradiciones que la gráfica popular mexicana hace uso de ellos. Este componente a diferencia de otros países se utiliza con diversos fines y hace uso del lenguaje característico del mexicano, el sentido del humor y el doble sentido son utilizados sin prejuicios. Es un recurso utilizado en muchos comercios para publicitarse o incluso se usa como el mismo nombre del establecimiento, un ejemplo palpable aparece en la Figura 7 "Salón Venus" en una clara e inequívoca referencia a los placeres de la vida. No queda claro si su uso es con una intencionalidad de venta, pregnancia a la mente o simplemente su uso es de carácter inconsciente. Muchos de los ejemplos de este breve análisis evidencian la importancia del uso del lenguaje y su representación en el grafismo, nos sitúan ante el reto de retomarlo como objeto de estudio con más profundidad, sin embargo se considera que este acercamiento proporciona elementos suficientes para destacar su importancia en la identidad de la gráfica popular mexicana.

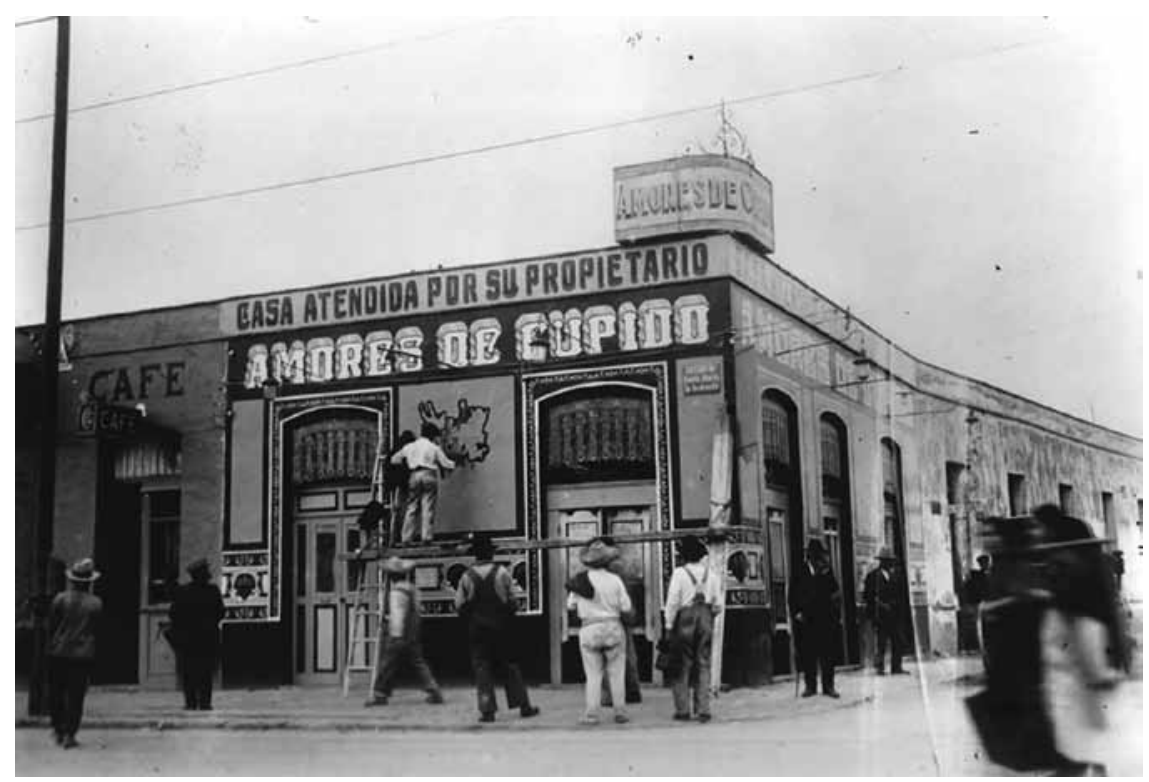

Figura 7. Fachada del expendio de pulque Salón Venus (Relatos e historias en México, 2019, s/p). 
Sin embargo, no podemos dejar de lado los procesos de producción e interpretación que parecen estar mediados por el contexto puesto que varios autores establecen que desde el contexto se articulan saberes que condicionan las formas de entender e interpretar por reglas adquiridas a través de una experiencia y aprendizaje, que en éste caso se refiere a lo visual, cabe mencionar que éste proceso no es diferente para cualquier manifestación gráfica; Esta postura permite visualizar a la gráfica popular -considerando sus orígenes hasta su evolución a la gráfica vernácula-, como referencia para el Diseño Gráfico desde las similitudes que han ido forjando a lo largo de sus múltiples manifestaciones de las cuales se podrían considerar las siguientes:

1. Se originaron a partir de fenómenos sociales.

2. Han contribuido con una construcción y manifestación social siendo actores en la transformación de una realidad específica.

3. Han sido detonadores de diversas Revoluciones de ideas.

4. Emiten mensajes que se constituyen en referentes simbólicos.

5. La composición icono-tipográfica en una jerarquización determinada por el destinatario.

6. Han reconocido y aplicado a la imagen gráfica como parte de la vida cotidiana.

7. Se han adecuado a la evolución en los materiales para su reproducción, en el taller de la gráfica popular por ejemplo, pasaron del zinc o la madera al moderno linóleo, por su fácil manejo y precio más accesible.

8. Tienen como objetivo comunicar un mensaje como condición básica consciente o inconsciente.

9. Reconocen a la hibridación y a lo arbitrario como parte de su evolución e identidad.

10. Comunican un mensaje, condición básica consciente o inconsciente, expresión por eso la importancia en los detalles, el color y la composición.

11 Tienen un destinatario específico.

12. Consideran al boceto como parte de un proceso para generar un mensaje visual.

13. Aplican recursos gráficos y códigos estilísticos.

14. Contemplan un método que en el caso del TGP iniciaba con investigar el tema a tratar, con el fin de identificar los elementos esenciales, para continuar con propuestas tanto colectivas como individuales que se socializaban para llegar a un acuerdo y finalmente realizar el grabado.

15. Manejan el realismo como lenguaje estético para su fácil identificación, lo que se definía en función al tema a tratar y como ya se ha mencionado al público al que va dirigido el mensaje.

16. Son prácticas de carácter no oficial con un lenguaje propio que expresan una visión peculiar de su entorno opuesto a los discursos establecidos por el arte.

17. Rigen sus concepciones estéticas a partir de la simplicidad, lo que permite procesos intelectuales sencillos para ser comprendidos.

18. Consideran la diversidad en los soportes utilizados y la intención comunicativa.

19. Sus principales actores han sido todos aquellos que de alguna manera se han relacionado con la expresión y representación gráfica, en su mayoría por artistas interdisciplinarios logrando una influencia en la cultura nacional con una misma visión, construir un lenguaje visual para difundir mensajes específicos a públicos específicos. 
20. Han generado una memoria social y han sido parte del inconsciente colectivo. Tomaron fuerza el siglo pasado en las escuelas y sobretodo con los movimientos de la LEAR y la TGP.

Tales manifestaciones observables en la gráfica popular actual, entendida como una manifestación social gráfica inherente a la cultura visual y al lenguaje cotidiano, son el reflejo de un diseño regional como resultado de la maduración del grafismo popular de principios de siglo XIX. La evolución del pensamiento visual ha sido una actividad del desarrollo de localidades, con una carga simbólica y semántica exclusiva de su vida cotidiana gracias a un ambiente diverso y complejo. Esta experiencia visual e intelectual le ha otorgado al Diseño mexicano el reconocimiento y apropiación de elementos gráficos plásticamente exclusivos de una manifestación o expresión única en su género permitiendo ser parte de una identidad local y nacional.

\section{Conclusiones}

La Gráfica Popular es una clara muestra del crisol de elementos propios de una cultura tan diversa como la mexicana, es el resultado de siglos de movimientos sociales y reflejo de una idiosincrasia producto de un mestizaje y una forma de vivir e interpretar la realidad cotidiana. Su vasto universo de elementos icónicos, tipográficos, cromáticos y lingüísticos que muestran esa heterogeneidad propia de una cultura tan diversa y rica en tradiciones y personas. Este breve análisis proporciona elementos necesarios para identificar y clarificar la importancia que la gráfica popular tuvo y tiene en la historia del diseño gráfico mexicano, lo sitúa como un referente no sólo en los albores de su nacimiento, sino como un elemento de influencia actual y vigente. Es importante señalar que los ámbitos de acción de cada uno tienen sus semejanzas y diferencias, sin embargo esto no los excluye uno del otro, por el contrario se complementan e integran. Quedan muchos vacíos de información y sería importante llenarlos con investigaciones futuras, puesto que hay algunas dimensiones propias de la gráfica popular que seguramente aportarían nuevas evidencias como por ejemplo el impacto social y político, así como también la observación del mismo como fenómeno de comunicación de masas. La identidad misma de esta gráfica ofrece también variados y complejos campos de estudio, es substancial referirse a esta dimensión bajo distintos enfoques los cuales tampoco se abordaron en este artículo y que serán materia de análisis futuros en el ámbito comunicacional. Para finalizar se puede aseverar que la trascendencia de la gráfica popular es de un valor enorme, no sólo para el diseño gráfico sino también como un elemento socio cultural más allá del plano comunicacional ya que es pieza innegable del ser y el estar de una cultura en estos tiempos de una gran pérdida identitaria de los individuos bajo un mundo digital y globalizado. 


\title{
Referencias Bibliográficas
}

Checa-Artasu, M. y Castro, P. (2008). "Notas para conceptualizar la gráfica popular Mexicana”. Gazeta de Antropología, 24 (2), 46. México

Gato pardo (2017). "80 años de historia del Taller de Gráfica Popular". Recuperado de: https:/gatopardo.com/opinion/emiliano-ruiz-parra/historia-del-taller-de-graficapopular/

Interior gráfico (2007). "La gráfica en la primera mitad del siglo XX en México”. Recuperado de: https://www.interiorgrafico.com/edicion/cuarta-edicion-noviembre-2007/la-graficaen-la-primera-mitad-del-siglo-xx-en-mexico.

La ciudad de México en el tiempo (2017). Recuperado de: https://es-la.facebook.com/ laciudaddemexicoeneltiempo/photos/la-pulquer\%C3\%ADa-amores-de-cupido-queestuvo-en-la-esquina-de-santa-mar\%C3\%ADa-la-redonda/1642012099154137/

MXCity (2016). "La fabulosa historia de la gráfica popular mexicana”. Recuperado de: https:// mxcity.mx/2016/11/la-fabulosa-historia-la-grafica-popular-mexicana/

Relatos e historias en México (2019). Recuperado de: https://relatosehistorias.mx/estasemana/las-pulquerias-templos-de-la-musica-y-el-arte-popular

Think Tank (2016). “Gráfica popular mexicana”. Recuperado de: https://thinktankmedia. $\mathrm{mx}$ /grafica-popular-mexicana/

Troconi, G. (2018). Diseño gráfico popular. México: Artes de México.

UAEM (2015). “Antecedentes del diseño gráfico en México". Recuperado de http://ri.uaemex. $\mathrm{mx} /$ bitstream/handle/20.500.11799/31259/secme-17739.pdf?sequence $=1$

Zonezero (2018). "Exposiciones fotográficas". Recuperado de http://v1.zonezero.com/ exposiciones/fotografos/soto/2.html

\begin{abstract}
The popular graphic is a communicational phenomenon that is generated in urban environments and represents the graphic imagination of a society as well as the essence of its culture. The analysis and study of the plastic and aesthetic elements that are part of the popular Mexican graphic are fundamental to understand the identity of the graphic design of this country. This research documents and analyzes the main graphic references that make up the broad universe of urban popular graphics, its actors, its needs and the sometimes involuntary contribution to a unique and differential aesthetic as a piece of a culture that identifies and distinguishes itself for its colors and the drama in its images to the rest of the other countries. This research is carried out based on the historical - logical and analytical - synthetic methods. Its characteristics, peculiarities and direct and indirect effects are shown in Mexican graphic design. The results of this research can help to build a historical and referential framework of the fundamental traits that gave rise to the current graphic design, as well as help to understand the context and needs that originated it and on which a large part of its identity rests.
\end{abstract}

Keywords: Popular graphic - Culture - Society - Identity - Mexican graphic design. 
Resumo: O grafismo popular é um fenômeno comunicacional que é gerado em ambientes urbanos e representa a imaginação gráfica de uma sociedade, bem como a essência de sua cultura. A análise e o estudo dos elementos plásticos e estéticos que fazem parte do popular gráfico mexicano são fundamentais para entender a identidade do design gráfico deste país. Esta pesquisa documenta e analisa as principais referências gráficas que compõem o amplo universo da gráfica popular urbana, seus atores, suas necessidades e a contribuição às vezes involuntária a uma estética única e diferencial como peça de uma cultura que se identifica e se distingue por suas cores e o drama em suas imagens para o resto dos outros países. Esta pesquisa é realizada com base nos métodos histórico - lógico e analítico - sintético. Suas características, peculiaridades e efeitos diretos e indiretos são mostrados no design gráfico mexicano. Os resultados desta pesquisa podem ajudar a construir um referencial histórico e referencial dos traços fundamentais que deram origem ao atual design gráfico, bem como ajudar a compreender o contexto e as necessidades que o originaram e sobre os quais repousa uma grande parte de sua identidade.

Palavras chave: Gráfico popular - Cultura - Sociedade - Identidade - Design gráfico mexicano.

[Las traducciones de los abstracts fueron supervisadas por el autor de cada artículo] 